\title{
Modeling of processes of wastewater treatment from nitrogen compounds in the trickling biofilter
}

\author{
Elena Gogina and Olga Yantsen* \\ Moscow State University of Civil Engineering, Yaroslavskoe shosse, 26, Moscow, 129337, Russia
}

\begin{abstract}
At least $70 \%$ of WWTP of small capacity in Russia include biofilters, that's why development of new technologies for treatment and methods of reconstruction are the points of great interest This abstract describes the methods and techniques of biofilters reconstruction to achieve desired water quality. The presence of biogenic compounds $\left(\mathrm{NH}_{4}\right.$, $\mathrm{PO}_{4}$ ) in the water body are one of the causes of eutrophication. The article considers the methodology of modeling processes of wastewater treatment in the biofilters: The results of sanitary - chemical researches and researches of the formed biomass are given. Based on the obtained data, laboratory models for hydraulic modeling and simulation of denitrificationnitrification processes on biofilters were developed. Modified mathematical model for calculating the height of the biofilters received specific mathematical dependences for the studied feed material.
\end{abstract}

\section{Introduction}

Water bodies are the basis of environmental safety and comfort of the population living in cities and towns. Availability of water and wastewater systems is a mandatory element of a comfortable environment for human life. Wastewater treatment is an important part of urban engineering systems. Modelling of wastewater treatment processes is the most important factor in the management of urban life support systems [1].

Wastewater treatment system is part of must ensure the quality of the water in the water bodies. This issue is as relevant for small towns as it is for big cities.

The experience gained speaks in favour of biological methods (based on natural processes of microbial life activity) of waste water treatment that show maximum efficiency when removal of biogenic compounds is needed. Moreover, vast majority of waste water treatment plants have facilities of biological treatment.

In Russia the norms for discharge into water bodies does not vary depending on the amount of discharged waste water, unlike many other countries, particularly the European Union.

Thus, in Russia the issues of intensification of processes of small capacity wastewater treatment plants are very important.

\footnotetext{
Corresponding author: YantsenOV@mgsu.ru
} 
A significant part of the low capacity waste water treatment plants in Russia includes biofilters. Thus, the optimization of the biofilters is the relevant objective up-to-date [2].

\section{Materials and methods}

Process modeling can be divided into 3 parts:

- $\quad$ biological process modelling and biomass analysis;

- $\quad$ hydraulic modelling;

- Mathematical model, based on the results.

A laboratory model with 4 alternating zones of nitrification and denitrification was developed. The studies were carried out on artificial waste water based on pepton. The model worked in two modes: with nitrate water recirculation (stage 1) and without (stage 2).After the positive results of the model studies in the laboratory, the semi-production model with real wastewater was studied (stage 3)[3].

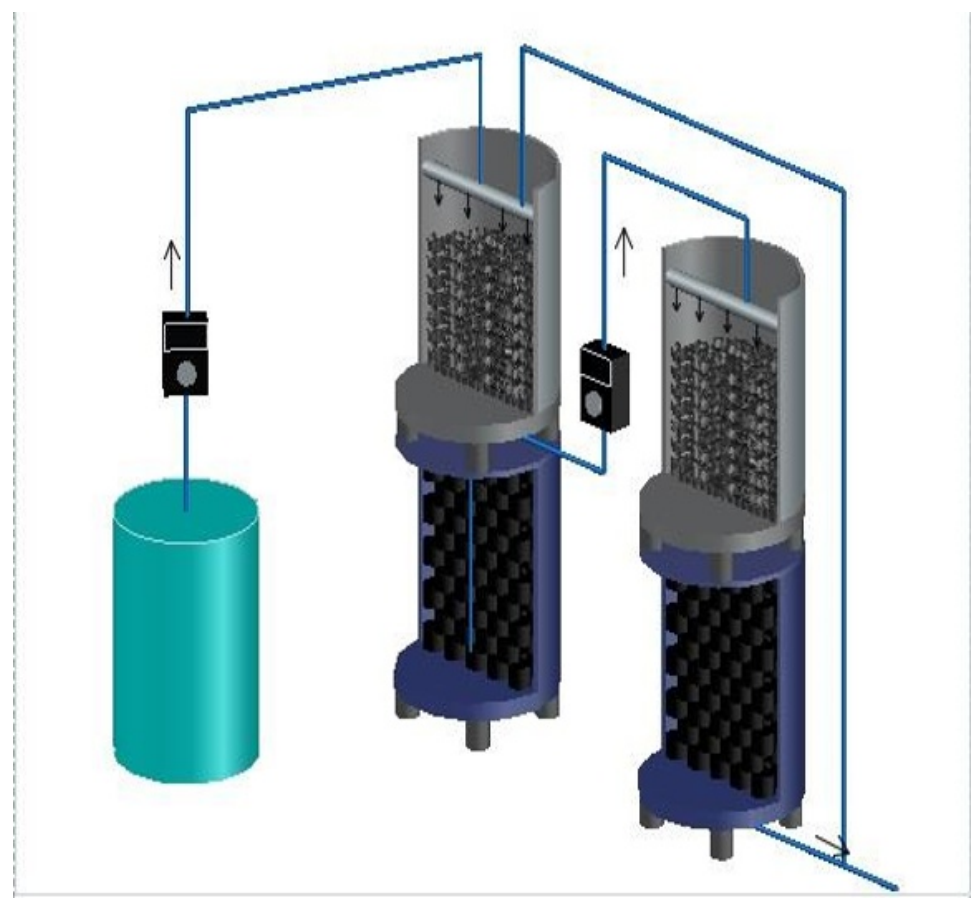

Fig. 1 Shows the laboratory model under study at stage 3

\section{Modeling of biological processes}

Biofilter is a reactor with feed, on which biofilm is formed. Biofilm can be defined as colonies of microorganisms which vital activity provide removal and treatment of pollutants of wastewater.

The feed should provide proper work of microorganisms that means steady income of nutrients and free access of oxygen. In this viewpoint high efficiency of work of biofilters is a matter of hydrodynamic and biological factors [4].

The model of trickling biofilter worked for six months in each mode. The best results were in the nitrate water recirculation mode (stage 1), so the model work on real water (stage 2) was also carried out in the recirculation mode. 
First of all, it is possible to evaluate the work of the biofilter using sanitary and chemical analyses 3 th stages results are presented in table 1 .

Table 1. 3th stages results

\begin{tabular}{|c|c|c|c|}
\hline & Step & NH4-N & BOD5 \\
\hline Sample & & $(\mathrm{mg} / \mathrm{l})$ & $(\mathrm{mg} / \mathrm{l})$ \\
\hline \multirow{2}{*}{ Waste water } & 1 & 21.65 & 95.0 \\
\cline { 2 - 4 } & 2 & 24.82 & 18.27 \\
\hline \multirow{2}{*}{ Treated water } & 1 & 14.25 & 20.38 \\
\cline { 2 - 4 } & 2 & 0.19 & 3.28 \\
\hline Norms of discharg & & 0.39 & 3 \\
\hline & & & \\
\hline
\end{tabular}

Biofilm showed in fig. 2 .
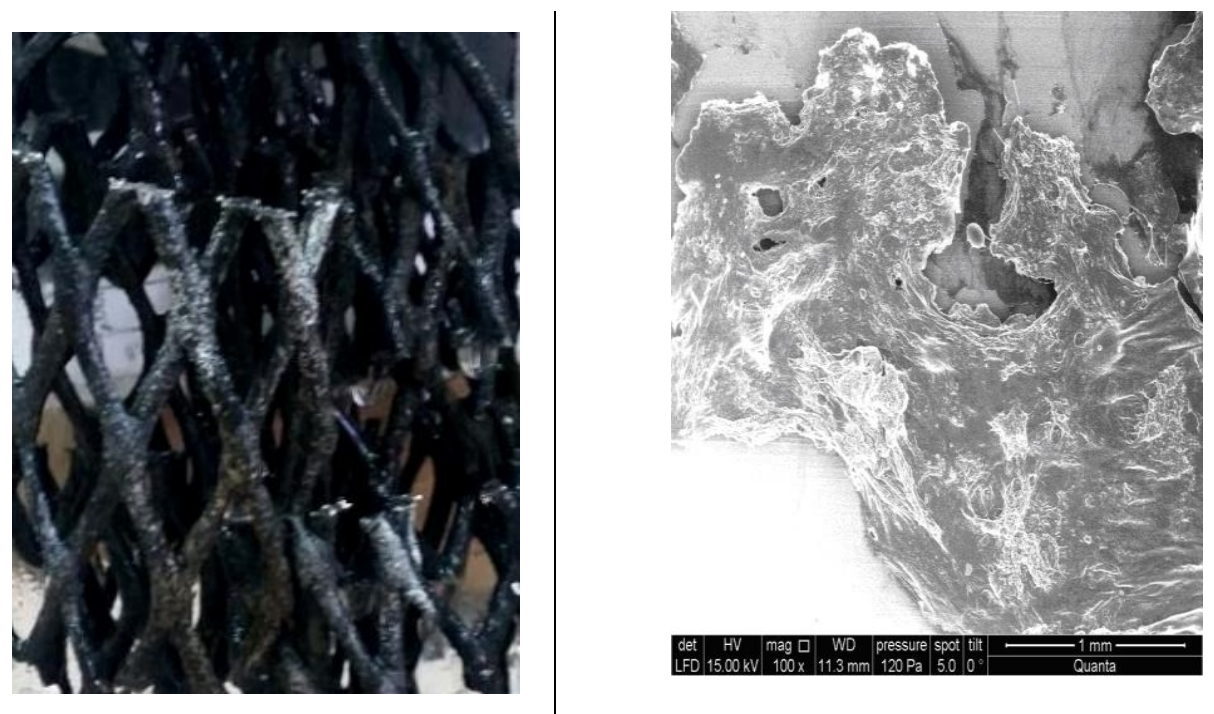

Fig. 2. Biofilm

The biofilm was located in a thin layer throughout the feed material. For this type of film, experimental proof is obtained that the processes occurring in them are described by kinetic equations.

\section{Hydraulic modeling}

The research included additional test to define contact time of waste water with feed. The factor of time has a serious action upon biochemical processes in biofilters that means that intensity and efficiency of treatment also depend on the length of the path to pass by the drops of waste water on the feed's surface. According to above a number of experiments to determine a contact time was carried out to establish optimal operation mode.

The time of presence of waste water in the feed has a significant influence on processes of biochemical oxidation in biofilters that means that intensity and efficiency of treatment processes also depend on the length of the path drops pass on the feed surface. As a result 
there was a number of experiments carried out to determine time of contact of water with feed surface. The cylindrical loading material presented in figure 1 was investigated

First a concentrated solution of dye was put into the lab model to define its concentration change in output water by means of photocolorimetry. The samples at the output were taken through the certain periods of time until coloration is absent $[5,6]$.

Based on the results, graphs of the dye concentration dependence on the sampling time were constructed using a pre-built calibration curve, which is based on the results of determining the optical density of a number of standard dye solutions with different concentrations. Then the area of the figure obtained on the chart and the static moment of the plane figure relative to the ordinate axis are calculated.

Contact time was defined as the center of gravity of a flat figure.

After processing the results of the experiments in logarithmic coordinates, it was found that at the height of the layer of the feed material $H=1 \mathrm{~m}$, the formula takes the form:

$$
V=57 * L^{*} q^{-0.2}
$$

where $V$-speed,

$q$-hydraulic load.

\section{Mathematical model, based on the results}

Non-stationary equation of material balance of substrate mass for a relatively unlimited area of a thin active layer of biofilm for a cylindrical feed material:

$$
D_{L}\left(\frac{\partial^{2} L}{\partial r^{2}}+\frac{1}{r} \frac{\partial L}{\partial r}\right)-R_{L}=\frac{\partial L}{\partial r},
$$

where $t$ - the time,

$r$ - radial coordinate,

$D_{L}$ - is the molecular diffusion coefficient of substrate in the biofilm,

$R_{L}$-is the kinetic rate of reaction of utilization of the substrate. The most common model for the rate of reaction $R_{L}$ in the absence of inhibitory process of biooxidation is described by the known equation Mono,

$$
R_{L}=K_{1} \cdot L
$$

where $K_{1}=\frac{\rho_{m}}{K_{m}}$,

$\rho_{m}=\frac{\mu_{m} \cdot \chi}{y}$, (the reaction of the 1 st order)

$y=\frac{d \chi}{d L}-$ the ratio of substrate to microbial biomass.

$\chi$ - concentration of active biomass of microorganisms inside the biofilm,

$K_{m}$ - half-saturation constant,

$\mu_{m}$ - maximum specific growth rate of microorganisms. 
As a result of mathematical transformations of the non-stationary equation of the material balance of the mass of the substrate, we obtain the formula:

$$
H=\frac{F \cdot V}{F_{\delta} \cdot K_{L}(1-A)} \cdot \ln \frac{L_{0}}{L_{S}}
$$

where $S$ - height of the biofilter,

$V$ - speed of water flow,

$F$ - sectional area of biofilter,

$F_{\delta}$-surface area of biofilm,

$K_{L}$ - coefficient of mass transfer,

$L_{0}, L_{S^{-}}$the parameters of the incoming and treated water

Thus, the height of the biofilter depends not only on the required degree of purification, the parameters of the incoming water, but also on the type of feed material (the amount of biofilm formed). To determine the speed $\mathrm{V}$ for the test feed material, the time dependences of the residence time on the hydraulic load, the rate of movement of waste water passing through the biofilter body were obtained.

In the resulting formula for calculating the height of the filter, you must substitute the known values for the speed of movement of water, sanitary and chemical parameters of incoming water in BOD5 or $\mathrm{NH}_{4}$, the required values of purified water and the calculated coefficients.

The resulting height of the biofilter should be divided by the number of zones.

\section{Conclusions}

1. Studies of the system of denitrification-nitrification using biofilters have shown the feasibility of its use for deep treatment of wastewater from nitrogen compounds with the provision of regulatory indicators for discharge into the reservoir of fishery importance.

2. The maximum effect on the removal of nitrogen is achieved by using a technological scheme that works with the recycling of nitrate water.

3. Microbiological studies of biofilm proving the possibility of using a mathematical model are carried out.

4. The velocities of water movement in the drip bio-filter for this feed material are obtained. 5. Modified mathematical model to calculate the height of biofilters.

\section{Prospects for implementation}

Thus, the closest mathematical model will be obtained to the process flow diagram with the previously designated charging material

\section{Discussions}

The presented studies has a complex nature, which will allow using biofilters, both in the reconstruction of existing structures and in the design of new ones [7-9].

Water balance is one of the key factors that concerns quality of life on Earth. There is a need to control discharge of various polluting compounds in water bodies among which there are biogenic compounds to be introduced with treated waste water. Biogenic compounds - nitrogen and phosphorus - leads to the eutrophication of water bodies that results in fauna exhaustion, rise of the cost of fresh water treatment and other 
consequences. Besides, process of eutrophication is reversible, so decrease of pollutants amount means restoration of quality of water resources [10-16].

This work was financially supported by Ministry of Science and Higher Education of the Russian Federation (\#NSh-3492.2018.8).

\section{References}

1. Nikolay Makisha, Olga Yantsen. J. Appl. Mech. and Mater. 587-589, (2014)

2. E. S. Gogina, O. V. Yantsen, O.A. Ruzhitskaya. J. Appl. Mech. and Mater., 580-583, (2014)

3. R. Wang, A. Terada, S. Lackner, B. Smets, M. Henze, S. Xia, J. Zhao, J. Water research, 43, (2009)

4. A. Kulakov, N. Makisha MATEC Web of Conf. Ed., 10019, (2017)

5. E. Gogina, O. Yantsen, Intern. J. of Appl. Eng. Res., 10, 24, (2015)

6. N. Makisha N., T. Kazimirova Principles of energy saving in water supply and sewage systems: MATEC Web of Conf., 04013, (2018)

7. N. Makisha, Ia. Panteleeva. Researche for waste water treatmenttechnology with low production of excessive active sludge MATEC Web of Conf. SPbWOSCE-2016 "SMART City"", 07015, (2017)

8. N. Makisha, E. Gogina. E3S Web of Conf. "Inter. Conf. on Advances in Energy Syst. and Environmental Engin., ASEE 2017", 00109, (2017)

9. N. A. Makisha Rresearch of ecology-friendly technology for elimination of ammonium from waste water through the use of floating bed, E3S Web of Conferences Cep. "International Conference on Sustainable Cities, ICSC 2016", 01002, (2016)

10. R. Zyłka, W. Dabrowski, E. Gogina, O. Yancen. J. Ecol. Eng. 269-275, 19 (4), (2018)

11. W. Dabrowski, R. Zyłka, P. Malinowski, D. Boruszko, E3S Web of Conf., (2017)

12. A. Ginzburg, L. Shilova, A. Adamtsevich, L. Shilov, J. of Appl. Engin. Sc., 457-460, 14(4), (2016), DOI: 10.5937/jaes14-12567

13. O. Ruzhitskaya, O. Yantsen, Inter. J. Appl. Engin. Res., 3496-3498, 11 (5), 2016

14. E. S. Gogina, O. V.Iantcen, O. A. Ruzhitckaia, R. Zhilka, D. Boruzhko, Water and Ecol., 35-45, 67(3), (2016)

15. E. Gogina, O. Ruzhitskaya, V. Shmalko, MATEC Web of Conf., 09016, 178 (2018)

16. E. Gogina, O. Ruzhitskaya, V. Shmalko, MATEC Web of Conf., 09015, 178 (2018) 